\title{
CHALLENGES \\ OF TRANSLATION PROCESS RESEARCH \\ AT THE WORKPLACE
}

\author{
Maureen Ehrensberger-Dow \\ Zurich University of Applied Sciences (Switzerland) \\ ehre@zhaw.ch
}

\begin{abstract}
Translation usually takes place at translators' workplaces, yet much translation process research refers to data collected under controlled conditions such as the classroom or the lab. Pursuant with recent descriptions of translation as a situated activity comes the necessity of investigating that activity where and when it occurs. Many of the methods that have proved useful in the lab have also been applied in the field, and some of the challenges associated with investigating translation at the workplace are common to any kind of empirical translation research. However, certain workplace constraints present special challenges to everyone involved. Some solutions that were developed for a workplace study in Switzerland may prove useful in other investigations and might allow new questions to emerge in this developing field.
\end{abstract}

\section{Kurzreferat}

Übersetzen findet für gewöhnlich am Arbeitsplatz von ÜbersetzerInnen statt, doch ein Grossteil der Übersetzungsprozessforschung bezieht sich auf Daten, die in einem kontrollierten Umfeld wie dem Klassenzimmer oder dem Labor erhoben wurden. Neueren Beschreibungen des Übersetzens als situationsgebundene Tätigkeit entsprechend besteht die Notwendigkeit, diese Tätigkeit dann und dort zu untersuchen, wann und wo sie ausgeübt wird. Zahlreiche Methoden, die sich im Labor als nützlich erwiesen haben, wurden auch im Feld angewendet und einige der Herausforderungen, die mit der Untersuchung des Übersetzens am Arbeitsplatz verknüpft sind, sind jeder Art von empirischer Übersetzungsforschung gemein. Dennoch stellen einige Einschränkungen am Arbeitsplatz für alle Involvierten eine besondere Herausforderung dar. Gewisse Lösungen, die für eine Arbeitsplatzstudie in der Schweiz erarbeitet 
wurden, könnten für andere Untersuchungen hilfreich sein und neue Fragestellungen in diesem sich entwickelnden Gebiet hervorbringen.

Keywords: Translation processes. Workplace research. Screen recordings. Professionals. Language service provider.

Schlagwörter: Übersetzungsprozesse. Forschung am Arbeitsplatz. Bildschirmaufnahmen. professionelle ÜbersetzerInnen. Sprachdienstleister.

Manuscript received on March 31, 2013 and accepted on September 25, 2013. 


\section{Introduction}

Graduates of our programs report that some of their courses prepared them for the realities of the professional translation workplace but that the range of tasks they were expected to perform there often surprised them. Some of them discovered that much of their work time was spent not just translating source texts in one of their languages into target texts in another. Instead, adapting texts for different readerships, editing, post-editing, revising non-native users' writing, and proofreading seemed to have become a big part of their brief. Developments in software applications and business processes in many translation companies have kept pace with some of these changes, but relatively little research has been done in the workplace to determine how professional translators are coping with the new demands placed upon them. Since professional translation is an economic activity, there are commercial interests and needs to consider. As Martin (2007: 60) puts it, translators must "balance risks and resources" to achieve economical "fit-for-purpose" translation, with quality demands ranging from modest (e.g., for gist translations of content for company-internal use) to extremely high (e.g., for image-relevant or legally binding material). Throughout the process, translators occupy a central position as experts in the complex system of translational action (cf. Holz-Mänttäri 1984), managing their attentional resources (cf. Campbell \& Wakim 2007) and bringing various types of competence to bear in order to complete the task at hand.

Current models of translation competence, which outline the expert knowledge and cognitive components assumed to be necessary for effective translation work, recognize the situated nature of translation to various degrees. The best-known model, proposed by the PACTE group (e.g., 2003, 2011), represents translation competence as comprising six interacting sub-competences or components. One of these, the instrumental sub-competence, underlies research and information technology skills. The psycho-physiological components in their model include cognitive/behavioral components and psychomotor mechanisms, which clearly relate to interacting with the environment. With her model of translation competence, Göpferich (2008, 
2009) suggests that the sub-competences and other components of translation competence are necessarily embedded in working conditions and influenced by external sources such as translation software. However, most of the studies about translation competence have investigated differences between groups (e.g., students and professionals or translators and non-translators) in controlled settings such as university classrooms or labs or are based on surveys of practicing translators and/or their employers (e.g., Lafeber 2012). Putting aside for now the question of whether all professionals can be assumed to be competent or indeed what it means to be competent, the issue of how factors at the workplace can influence translation performance remains.

Certain developments in translation studies reflect an appreciation of translation as a system that involves not only multiple agents but also human-computer interactions (e.g., Risku 2009, 2010; O'Brien 2012). As Risku (2002: 529) points out, "Translation is done not only by the brain, but also by complex systems, systems which include people, their specific social and physical environments and all their cultural artifacts." Some researchers have investigated the realities of the translation workplace with respect to team interactions, roles, and daily activities (e.g., Hébert-Malloch 2004; Koskinen 2008; Kuznik \& Verd 2010; Risku 2009). Others have done ethnographic research at the workplace to explore questions related to resources and tools (e.g., Désilets et al. 2009; Karamanis, Luz \& Doherty 2011; Le Blanc 2013). Most of this workplace research has been based on interviews and (participant) observation. However, the possibilities offered by other techniques that have become common in translation process research in controlled settings have not yet been fully exploited in workplace settings.

Understanding the situated activity of translation obviously requires investigating professional translation activity in situ. According to Risku (2009, 2010), a situated cognition perspective can account for the special role of context and tools to explain their impact on the translation process and the quality of the product. In a similar vein, Muñoz (2012a: 179) points out that considering translation performance in terms of mental load and automation could have implications for professional practice. This is echoed by Christensen (2011: 139-140) in her plea for more workplace research:

What we need to do is to combine investigations on what happens in a translator's mind with what happens elsewhere, e.g. in translators' hands, in their computers, on their desks, in their work environment and in their dialogues and interactions with their collaboration partners.

The realities of the workplace, though, demand compromises that fly in the face of proposals and attempts to standardize methods in translation process 
research (e.g., Muñoz 2010, 2012b). This paper addresses some of the challenges encountered in a recently-completed project at a language service provider (LSP) in Switzerland, explains how they were dealt with, and makes some modest recommendations for future research. The aim is to open up the discussion of good practices of applied translation process research.

\section{A Swiss workplace investigation}

As part of our institute's Capturing Translation Processes (CTP) project, staff translators were monitored at their usual workplaces over a period of approximately six months and took part in experiments in our institute's lab (Ehrensberger-Dow \& Massey 2013; Ehrensberger-Dow \& Perrin 2013). The original motivation for including professionals in the project design was not only to test predictions derived from competence models but also to investigate translation at the workplace. Another important consideration was that the project was funded by a special program, since disbanded, of the Swiss National Science Foundation to encourage industry involvement in applied research projects. According to the conditions of the program, at least 30\% of the overall cost of the project had to be carried by the industry partner, whether in cash or services in kind. One of the first challenges for the project leaders was therefore to find a willing partner and to convince them to commit themselves to a substantial investment of money and/or time in the project. This and some other challenges that arose during the course of the project are described in the sections below.

\subsection{Finding the right partner}

In Switzerland, the dominant language for professional translation work is German, either as the target from English, French, or Italian, or as the source for translation into those three languages. For our project, we were interested in finding an LSP that had a high volume of work in these language versions. The company we approached specializes in the financial and life sciences sectors and offers a comprehensive range of services for end-to-end multilingual text management, which is a good fit with the curriculum of our BA and MA degree programs. As the largest employer of staff and free-lance translators in Switzerland, the company is the single most significant contact for graduates from our programs. Perhaps for this reason, the executive board indicated that they would be willing to cooperate in our institute's research project and approved an internal budget on the basis of our executive summary and 
calculations. The time between initial contact with the LSP about the project and board approval was about two months.

Among other services in kind, the LSP board agreed to place junior and senior translators with various language combinations at the disposal of researchers on our team on a regular basis for a certain number of hours per month and to allow us to examine computer loggings and screen recordings of those translators' translation and revision processes. They designated a project manager to handle all contacts between their translators and our research team. In return, the LSP expected to receive answers to specific research questions concerning strategic and instrumental sub-competence as well as to be offered bespoke professional development courses designed to increase the efficiency and effectiveness of working practices among their staff. The LSP's involvement was also to be acknowledged in project websites as well as in presentations and publications pertaining to data collected from its translators.

Language versions and text genres are obvious prerequisites for determining whether the right partner has been found, but other factors are also important. For example, the partner's reputation in the market, both as a service provider and an employer, gives an indication of whether its workplaces and procedures are representative. Translations done in a company that is not known for its reliability may not reflect models of good practice. An LSP's quality assurance and official certifications provide indications of whether its translation work is considered fit for the market. For longitudinal research, the sustainability and size of an LSP can be critical to a project's success. A reasonably large firm can usually handle the disruptions and additional demands on staff time that involvement in a research project entails, whereas a small firm might be overwhelmed by unexpected problems or delays. Fluctuations in workload or staffing can affect the outcome of a project, especially if they are not anticipated in the initial design of the study.

\subsection{Designing the study}

The CTP project was designed to acquire as much information as possible about translation processes in a naturalistic and non-invasive way, combining observation of the workplace, interviews, questionnaires, computer logging, and screen recordings as well as eye-tracking and retrospective verbalizations whenever feasible (see 2.5). Since the professionals' processes and retrospections provided a basis for comparison with students at various stages in the latter's careers, another challenge was to ensure at least partial comparability 
between the groups, task demands, and source materials for the professionals and the students.

\subsubsection{Groups, versions, settings}

The design of the main project originally included four different levels of experience (beginners, advanced students, relatively inexperienced professionals, and experienced professionals), two directions (into the first language/L1 or second strongest language/L2), two settings (workplace and lab), and three different language combinations (German with each of English, French, and Italian). One of the first compromises to a balanced design had to be made with respect to directionality, since the professionals at our LSP partner only translated into their L1. The second compromise concerned language versions. Since the LSP had a heavy workload of translations out of German, their primary interest was those versions. However, the LSP project manager understood that a comparison between language versions would be interesting and agreed to include translation from English into German as well. This was very important to the research team, because it is the most subscribed version in the institute's translation degree programs. Based on the same rationale, the design was also slightly modified for the student groups to ensure that enough translation processes into L1 as well as from German into English could be collected in the lab. The final compromise had to do with level of experience. Although the LSP officially has two levels of translator experience (juniors and seniors), in-depth discussions with management revealed that this distinction seemed to be related to length of time at their company rather than to overall experience or expertise. For this reason, the decision was taken to group the professionals together.

The gold standard of random assignment of participants to groups is far removed from the realities of workplace research. In a lab setting, students who are attending translation courses in various language combinations and both directions of a particular combination may be randomly assigned to a group. However, it would make little sense to do this with professionals who habitually translate one version of a language combination and in any case would be impossible in the workplace. The compromises that had to be made to the planned study groups and translation versions are probably typical of workplace investigations and point to the necessity of flexibility in this type of research. 


\subsubsection{Task demands}

Translation process research at the workplace can also be much more challenging than in the lab because the object of study can move between various agents and is not clearly delineated. For example, a translator might begin a translation task, realize that the job is too large to be done alone within the time available, ask one or more colleagues to help, split up the job, put it back together, review it, and send it to someone else for quality assurance before it is considered complete. Even in the relatively simple scenario with a single translator, the complexity of the translation process is obvious in the twelve stages described by Gouadec (2007: 14-21), ranging from getting the job to translating, checking, revising, and delivering the final version to the client.

Revision processes should be taken into account in workplace investigations, since the definition of translation work has broadened in recent years to include post-editing of machine translation output and revision of other people's texts (whether translations, adaptations, or original texts written by non-native speakers). Some aspects of checking or self-revision (Asadi \& Séguinot 2005; Englund Dimitrova 2005; Robert 2008) and so-called other revision (Brunette, Gagnon, \& Hine 2005; Mossop 2007) have been identified, but again there has been little investigation of translators and revisors at their workplace. If a translation job could be followed from a translator's to the revisor's workplace as it is sent to be revised, a realistic picture of professional translation and revision might emerge.

Our team decided to try to capture as much of the process as possible, from the point that a translator first accepts a job through quality assurance, if done, until the target text is sent back to the translation project manager for further processing. For our study, "task" had to be defined as anything that a translator at the LSP was expected to do in the course of producing target texts that were fit for purpose/delivery (cf. Martin 2007). The level of quality and the time available for the task were determined by the LSP's usual procedures and could not be influenced by the researchers. This presents obvious problems for comparisons of individual processes with processes produced by translators working at other LSPs or by students but does allow comparisons between groups of translators working for the same LSP. Indeed, one of the LSP's research questions was why translation from German seemed to be more time-consuming into some languages than into others. 


\subsubsection{Source materials}

The source texts that staff translators are confronted with at the workplace may be quite different from those chosen as stimuli in lab settings. This was made clear to us by a comment from a staff translator, translating what we considered a rather unexciting journalistic text in one of our experiments (e.g., Oh, this is fun). Cao and Zhao (2008: 29) point out that "Despite the long history of translation and multilingual practice at the UN, very little has been studied and written as to the nature and difficulties of translating documents at the UN". This is true not just of institutional translation but of many other professional settings. What we do know about source texts at the workplace tends to be based on personal experience or analyses of published output from institutions. It is much more difficult to get an overview of what kinds of source texts a typical LSP might have to deal with, since most of them work for various clients.

Analyses of translation processes often only make sense with respect to problems presented by source texts, so it is important to ensure that these are also available to the researchers. The LSP in our study defines source texts as belonging to one of over 40 categories. The category descriptors refer variously to the type of content (e.g., pharmaceuticals), corporate department (e.g., finance) or genre (e.g., directives), which may or may not be a useful categorization for analysis purposes. In any case, the translation processes of a representative selection of texts of the same genre, subject field, and length can be compared post-hoc across language combinations and versions.

Most workplace source texts are only translated once (and not by numerous translators, as happens in experiments or in the classroom) yet some of them might be translated into different languages, which could allow for interesting comparisons between combinations. Since the processes collected during a workplace project are part of the translators' normal workloads, researchers cannot count on having such comparisons at any particular point in time but should still prepare for them.

In our experience, source materials at the workplace comprise not only the texts to be translated but also the supporting or reference materials. Again, it is important that researchers have access to those materials, in order to be able to fully understand how translators use them during the translation process. This can be very difficult if they are confidential (see 2.4). 


\subsection{Recruiting participants}

A real challenge in workplace research is recruiting participants and keeping them on board throughout the course of a study. We convinced the executive board of the LSP quite quickly about the usefulness of our project but anticipated that it might be harder to convince professionals that involvement in empirical research might be more than just a bother. All of the translators based at the LSP's head office were invited to a short preliminary information session, in which the study methods, time commitment, and logistics were explained. Although the session was on company time, not all of the translators chose to attend, either because they had already decided whether they would participate or because they were in the middle of an urgent job. Most of the translators who came to the session did indicate their willingness to take part. Participation was voluntary, which meant that the translators were self-selected, interested, and probably quite highly-motivated. The positive aspect of this was that attrition was expected to be relatively low, but the negative aspect was that the sample could not be considered representative. It is impossible to know why a person chooses not to take part in a study, and it is rather unethical to ask. For example, we only found out much later that a couple of translators refused to become involved because they had heard we were planning to do something with their eyes (i.e., track eye movements).

With participation voluntary, the issue immediately arose as to how to attain the group sizes that we had anticipated in the study design. When we first planned the study, the LSP project manager informed us that there were large numbers of translators working in each version of interest, which were what we based our grant application and budget on. By the time the grant was approved and we began recruiting translators, circumstances had changed at the LSP and one language version (German-Italian) was no longer being done at the head office. Due to restructuring and natural attrition, the number of participants changed again, most noticeably in the German-French group, so that by the time data collection at the workplace actually began, almost a year after recruitment, the study had essentially become a comparison between English-German and German-English processes.

In complex workplace projects, a delicate balance has to be struck between recruiting participants, maintaining project momentum, and collecting reliable data. The time lag between initial recruitment and data collection at the workplace in our project certainly contributed to the attrition rate. If we had been in a position to collect workplace data immediately after recruitment, we would have had much larger groups. However, the decision was taken with the LSP project manager to launch the project and recruit translators before 
all of the software issues associated with recording processes at the workplace had been resolved (see 2.5.3). The reason for this was that translators knew that they would be asked to be involved in a research project, had heard something about the software issues, and needed to be informed about the study. Some of the translators who contributed to the main project by completing questionnaires (see 2.5.2) later left the LSP or were transferred to other locations, making further involvement in the study difficult or impossible.

\subsection{Maintaining confidentiality}

Anonymity is always important in empirical research, in order to protect the participants' identities and to heighten the objectivity of data analyses. For an LSP competing for market share, these concerns are compounded with serious reputational risks. An LSP must be protected from any hint that its translators' performance is being called into question, while at the same time researchers might be exploring possible weaknesses or potentials for increased efficiency. Texts that are being translated cannot be the primary focus of interest, since many are highly confidential and subject to special security considerations. For example, an extract from one of our LSP's brochures reads as follows:

THE ULTIMATE IN SECURITY

Do you work with confidential documents or sensitive information? With our services, you can rely on the highest standards of security. As well as using encrypted data transfer, we maintain strict confidentiality at all times. Whether you are entrusting us with a confidential memorandum containing the unpublished results of a study or your company's financial results, [LSP] guarantees maximum security coupled with top-quality service.

Workplace researchers must be prepared to observe this level of security and to treat all client data with absolute confidentiality. All identifying information should be removed from data for analyses, and any data or examples used for publication or educational purposes must be modified to ensure anonymity of the participants or be approved in advance by the LSP. In some cases, security considerations might preclude the possibility of recording data on certain days from certain translators or from certain workplaces. In our study, for instance, one of the original questions that the LSP was interested in concerned texts that proved to be too sensitive for the research team to have access to. The research design and team need to be flexible enough to cope with such restrictions.

In other cases, time can work in the researchers' favor: certain texts are only sensitive until publication and afterwards become part of the public domain, so analyzing processes may be unproblematic later. Our LSP set a 
default period of six months for the release of data, which meant that nothing concerning clients' texts could be removed from their premises before that time. In addition to all of our team members signing confidentiality agreements, the on-site researchers effectively became employees of the LSP during the data collection and data preparation phases of the study, bound by the same security restrictions as the translators they were investigating. As such, they acquired an insider status in the workplace that probably contributed to a level of rapport with the translators that might not have been possible otherwise.

\subsection{Collecting data at the workplace}

One of the most convincing arguments for workplace research is its ecological validity: investigating translation processes becomes truly relevant to translation competence and practice when the processes reflect actual practices of working translators and not artefacts of experimental settings and tasks. Our multi-method approach combines ethnographic observations, interviews, questionnaires, computer logging, screen recording, retrospective commentaries, eye tracking, version analysis, and translation evaluation whenever possible. It is relatively non-invasive and provides sources of both quantitative and qualitative data to obtain a rich description of translation processes (cf. Ehrensberger-Dow \& Perrin 2013). The multiple sources of data are crucial to this type of research: only by triangulating information from various perspectives can a complete pattern of the translation process emerge.

The following sections outline the challenges associated with applying various data collection methods in the workplace. In some cases, we found solutions that met our needs, and in other cases we had to make compromises. Some of those solutions and compromises were relatively easy to absorb into the project design, but others had consequences that threatened the credibility of the study.

\subsubsection{Ethnographic observations}

During the planning phase of a workplace study, researchers should try to create opportunities to spend time in the respective company or institution. It is only on the "translation floor" of an LSP that certain potentially interesting factors as well as problems can be identified and built into the study design. Factors such as economic, institutional, and technological influences on the work situation as well as the types of tasks that translators are usually engaged in (including expected quality level, deadlines, etc.) should be noted and 
included in design considerations as well as later in the translators' profiles. All of these factors are part of the real world that informs translators' mental representations and motivates their actions. Data from ethnographic observations can provide qualitative indicators that contribute towards interpreting the appropriateness of translation solutions with respect to the constraints that translators work under.

During the data collection phase in our workplace study, two researchers went in and out of the LSP offices two or three days a week for almost a year: the pilot testing began in January; the kick-off information session with the whole research team and participating translators was in March; actual data collection began the following week; translation process data was collected until August; related materials such as source texts and supporting documentation were compiled until October; and data preparation such as converting and backing up files was done on-site until November. By December, all of the workplace data were collected, stored at the LSP, and prepared for the time of their release to the research team for the analysis phase.

The on-site presence of the researchers in the workplace was much longer than had been anticipated for a variety of reasons. Because of new security regulations introduced by the LSP board, many of the processes done each day by the participating translators could not be included in the corpus, so the data collection phase was extended to be able to capture a representative number of hours from each of the translators. This made it impossible to finish data collection before the summer, which was when the LSP moved offices. That move affected most of the translators, further delaying the data collection and extraction of the relevant documentation for the project corpus. However, new research questions at the workplace emerged before, during, and after the move (see section 3). These might have remained hidden if data collection had proceeded according to the original plan.

The on-site researchers' involvement in the workplace was not ethnographic in the strictest sense (cf. Atkinson et al. 2001) because they were there to collect data and not work as translators, but both had been trained and had worked as professional translators. This may have contributed to their presence at their workplace being well accepted by the translators who were being monitored. Originally, the researchers' workstation was foreseen in an empty office at the other end of a long hallway from the translators. This was changed at the request of both, because the LSP project manager (a former translator and graduate of our institute) thought that physical proximity could improve the acceptance of the study. The workstation was then set up in the corner of an office with several participating translators. Although its 
location meant that the researchers had to be sure that their activities did not disturb the translators, it provided them with an insider's view of life at the LSP. Being in the translators' proximity also fostered informal contacts to such a degree that many data collection logistics were considerably facilitated (see 2.5.3). For example, without any special requests being made on the part of the research team, the manager responsible for the office move ensured that the researchers were allocated a workstation close to the translators in the new premises.

A comment by one of the LSP translators towards the end of the data collection phase nicely sums up the value of long-term researcher involvement in the workplace:

It's useful that you're actually here for quite some time and you're doing it regularly rather than just once. 'Cause if you did it, if you did it just once everybody would be sort of, feel slightly less comfortable or they wouldn't know what to expect and they would translate less naturally. (ProE4)

\subsubsection{Interviews and/or questionnaires}

Just as in any other type of translation process research, detailed metadata about participants need to be obtained at the beginning of their involvement in a study and updated if anything changes. Interviews or questionnaires can be used to elicit metadata, which include personal information (e.g., age, sex, handedness, eye color, linguistic biography, education), translation experience and level (e.g., student, freelance, staff, part-time, full-time), and workplace conditions (e.g., private or shared office, translation memory use). It can also be very interesting to obtain information about what participants consider their usual translating and revising procedures to be, in order to allow comparisons with actual practices. However, such preliminary interviews or questionnaires only provide researchers with information about what translators think they do or intend to do and their awareness of it. They do not necessarily tell researchers what translators actually do.

Trying to acquire as much information as possible about translators' practices and processes through interviews and questionnaires can actually be detrimental to a workplace monitoring study. If translators tell researchers about their practices in an interview and shortly afterwards are observed while translating, there is a risk of them becoming self-conscious about what they are doing, no longer behaving naturally, losing face, or questioning the point of other data collection methods. All of these possibilities would threaten the validity of a study that sets out to investigate what translators normally do at the workplace. To reduce this threat, it would be advisable to create a 
gap between obtaining self-report information and observing workplace practices. This gap can be produced through timing (i.e., having the preliminary interviews and questionnaires done far in advance of other data collection) or job assignments within the research team (i.e., having different types of data collected by different researchers).

In our project, the timing of the preliminary interviews was planned carefully and changes in the research team probably also contributed to creating plausible information gaps. The researcher who carried out most of the preliminary interviews left the team before the other data collection started, but of course the information he had collected stayed within the project. This might not have been as obvious to the participating translators, since they repeated some of that information to the on-site researchers. Having transcribed the questionnaires and interviews or at least having read through them before starting to collect the other workplace data, the on-site researchers found it quite easy to remember details about the translators and to gain their trust quickly.

Preliminary interviews and background questionnaires were done in a quiet room at the LSP premises. It could be argued that translators might not feel completely relaxed talking to a researcher about themselves, their work, and their working conditions while at the workplace, but there was no reason for us to believe they would be more relaxed in an unfamiliar setting such as
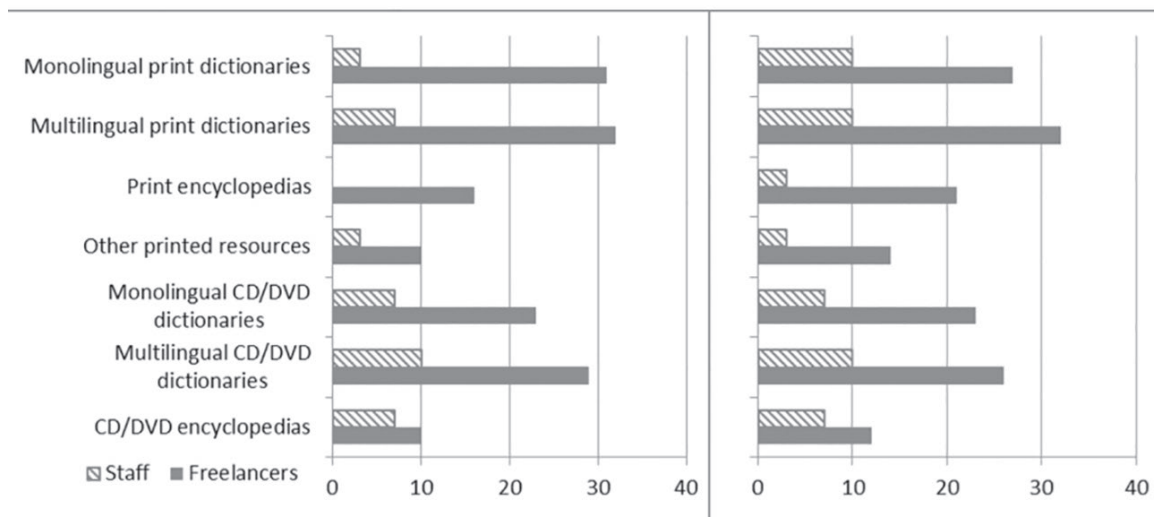

Figure 1. Percentage of "very often" / "often" responses by freelancers (n=110) and LSP staff translators $(n=29)$ to the question of whether a print or CD/DVD resource is consulted to solve linguistic or extra-linguistic problems. 


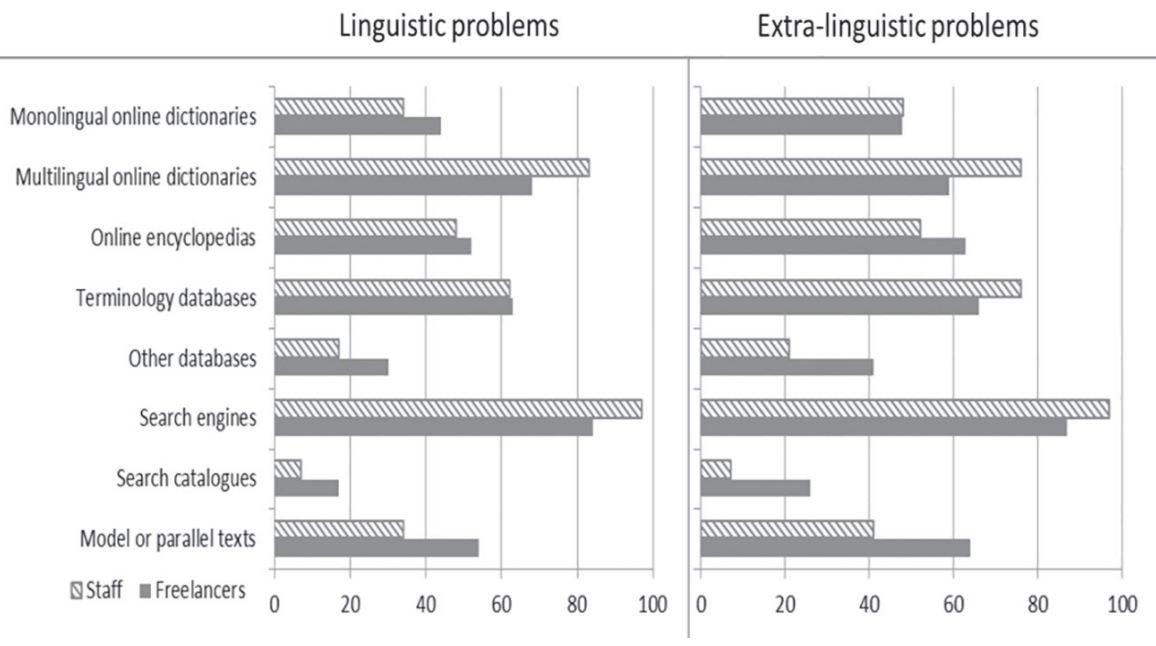

Figure 2. Percentage of "very often" / "often" responses by freelancers and LSP staff translators to the question of whether an online resource is consulted to solve linguistic or extra-linguistic problems.

in our lab. In any case, the sessions were on company time at the translators' convenience, so there was no choice about the location. Doing the preliminary sessions at the LSP's offices had the advantage that a member of our research team could spend some time on-site before the other workplace data collection started (see 2.5.1). None of the information at the preliminary sessions was recorded electronically, which meant that resources were required for the subsequent transcriptions and may have resulted in some loss of information. However, the simple pen and paper data gathering in the interviews seemed to have contributed to the informality of the situation, which may have helped to establish rapport with the translators.

We also used an online survey to collect information from the translators about their research behavior and tool use. Although this technique is not particular to workplace research, the data gathered in the preliminary interviews and ethnographic observations were very useful in tailoring the survey to the LSP's circumstances while still allowing comparisons with other groups of translators. For example, our survey with freelancers (Massey \& Ehrensberger-Dow 2011a) showed that they were far more likely to say that they used print and CD resources to solve linguistic and 
extra-linguistic problems than the LSP staff translators were (see figure 1) whereas the two groups reported similar behavior with respect to online resources (see figure 2).

The differences between the responses about print and CD/DVD use by the LSP staff translators surprised us and prompted a discussion with the LSP project manager and IT officer. We knew from our ethnographic observations that print dictionaries were readily available at the LSP (i.e., close to or on the translators' desks). The IT officer also informed us that a wide variety of $\mathrm{CD} /$ DVD resources had been installed in the LSP system. She speculated that they were so easily accessible that the translators might have thought of them as online. Another possibility might be that not all of the translators were aware of the resources that their employer had put at their disposal. In any case, the IT officer decided that it was time for an information update. Since being part of an organization can affect that organization's practices, workplace research often takes the form of action research (cf. Cravo \& Neves 2007). One of our study goals was to release expert knowledge to the organization, so we did not try to stop this action despite its precluding a validation of the survey data with observational data collected at the workplace later.

\subsubsection{Computer logging and screen recording}

In the workplace, computer logging is more commonly known as spyware and has received a great deal of bad press. One challenge in including it in a workplace study is to convince the translators that the motivation to use it is to gain information about translation processes and not about them. Another challenge is to sort out the keystrokes related to translation processes from those involved in unrelated tasks such as responding to email. We discovered, however, that the greatest challenge was to obtain a keylogger that could actually capture the data we were interested in, since everyone concerned had underestimated how difficult it would be to log translation memory input. For data security reasons, our industry partner wanted to have a custom-designed keylogger developed by their IT service provider to the specifications of our project team. The automatic logging was to be linked to the individual translator's login and designed so as not to influence the performance or integrity of the system. The keylogger tested reasonably well in isolation, but it turned out to be impossible with the allocated resources to achieve a solution that was capable of accurately logging keystrokes and translation memory input at the translators' own workstations.

The study design had foreseen automatic keylogging over an extended period and a short phase of screen recordings, but the decision was made 
partway through the study to shift the focus to screen recordings and to abandon the keylogger. Because screen-recording software slowed down computer responsiveness in pilot tests, a proxy solution was devised with the actual recording done on three "slave" computers that were linked to the translators' computers. Despite careful pre-testing, various new problems arose at the beginning of the data collection at the workplace. For example, the on-site researchers discovered that they needed to move the slave computer's mouse regularly or the screen saver would be activated, resulting in a useless recording of a potentially interesting process. The IT support staff's ingenuity at developing work-around solutions was much appreciated. By the second or third week of data collection, all of the software problems were solved and the translators seemed to have grown accustomed to the researchers' presence.

Issues concerning client confidentiality and translator privacy had to be dealt with delicately with respect to screen recording, and the whole process had to fit in smoothly with the workflow. The original plan was to have the researchers check the work assignments for the day and decide which processes to record and from whom, in order not to bother the other translators unnecessarily. However, the better solution turned out to be for the on-site researchers to contact the translators each morning to ask whether they had processes that could be recorded and for the translators to notify the researchers to interrupt the recording whenever they wanted. The IT support staff had arranged for a small notice to appear on the translators' screens while recording was on, so the translators always knew when they were being monitored. They notified the researchers to stop recording when confidential work suddenly had to be given priority but rarely did otherwise. The researchers had made it clear to the translators from the beginning that they were only interested in non-confidential translation processes. The fact that they were in the same room as the translators and could be observed cutting out sections of the recordings that were not related to translation probably contributed to the translators' relaxed attitude towards the monitoring. Although they had been told they could, none of the translators ever asked for any recordings to be deleted from the corpus.

Rather than being perceived as a bother, the necessity of communicating with the researchers several times a day seemed to have had a positive influence on the translators' motivation. Their interest in the study remained high throughout the 6-month data collection phase, and all of them said that they enjoyed being involved. This might call into question the representativeness of the translation processes collected in the study, since not all staff translators 
might be as motivated and interested as these ones were. However, the processes are rich in details about how professionals deal with translation tasks at their workplaces and can serve as a corpus to develop hypotheses to test with other groups.

\subsubsection{Retrospective commentaries and interviews}

On analogy to research that our team has done in controlled settings (e.g., Massey \& Ehrensberger-Dow 2011b), each of the participating translators was shown a 20-30 minute recording of one of their workplace translation processes and asked to comment on it. The verbalization sessions were scheduled as soon as possible after the process, in order to minimize memory effects, and long enough after to give the researcher time to prepare the recording. The maximum 24-hour delay set at the beginning of the study meant that one of the sessions had to be aborted, because the translator became tied up in work and could not do the verbalization when planned. A different process was chosen on another day. In general, processes were chosen based on convenience sampling (i.e., the processes that were done the day that a translator said he or she had the time or inclination to do a verbalization) and the researchers' observations of what seemed to be typical of a particular translator's workload. Since the verbalization sessions only began two months after the start of screen recording, the researchers had gained a fairly reliable impression of typical jobs by then.

The translators were asked to verbalize what they saw themselves doing and what was happening on the screen. Creating an information gap was difficult in this case, because the researcher listening to the verbalization was the same one who had made the recordings that day, selected the process to be commented on, and cut the video file to exclude anything unrelated to the translation process. Nevertheless, the translators verbalized a lot and about a wider variety of concerns than they had done when they had commented on their recordings in the lab. The comments that indicated metalinguistic awareness of what the participants were doing and why (i.e., not simply descriptions of the screen events or research activity) were extracted and coded in an iterative process with respect to their focus. The resulting codes were then grouped into six categories that ranged from a focus on the micro level of words and phrases to the translator as part of a system (see table 1 for a comparison of the comments about the lab and the workplace processes by the English-German and German-English translators). 


\begin{tabular}{|l|l|c|c|}
\hline \multicolumn{1}{|c|}{ Category } & \multicolumn{1}{c|}{ Examples from workplace commentaries } & Lab & Workplace \\
\hline $\begin{array}{l}\text { Words and } \\
\text { phrases }\end{array}$ & it's just a, a literal translation, which is useless & 27 & 57 \\
\hline $\begin{array}{l}\text { Sentence } \\
\text { structures }\end{array}$ & I've turned the sentence around in the English & 73 & 86 \\
\hline Text quality & that is not particularly nice English & 93 & 93 \\
\hline Loyalty to ST & the German actually uses the 'you' form & 67 & 93 \\
\hline Readership & because this is a journalistic article & 87 & 71 \\
\hline Accountability & I'll have to put a note in for the QA person & 27 & 93 \\
\hline
\end{tabular}

Table 1. Percentage of translators $(n=14)$ making comments in each category.

Almost all of the translators made comments at the workplace that reflected their awareness of their role in a service industry. These included mention of responsibility to the client, references to colleagues and quality assurance, and reminders to add things to the translation memory system. Katan (2009) also identified these multiple concerns in a survey of professional translators, who spread their loyalty across various focal points that included the source text, target text, and client.

After the commentaries about the workplace processes, the translators took part in an interview about their views of translation in general, their experience in the study, and their own practices. As our experience with students and teachers has shown (Massey \& Ehrensberger-Dow 2011b), viewing translation processes and reflecting on the process can have a learning effect. Several of the translators mentioned that they had become more aware of how they translate, as example 1 indicates.

(1) I think, my approach, generally, maybe that I noticed or that I became aware of again, is that I have a kind of an iterative approach to translation. (ProE2)

Others identified room for improvement, such as in example 2.

(2) Well, as I've said, not looking up stupid little words (laughs) and I'd like actually using my brain a bit more. (ProE1)

And, in line with Gouadec (2007)'s twelve stages, example 3 indicates that translators can become more aware that interlingual transfer is only part of their job.

(3) Because actually, when I do a translation I find that all of the kind of peripheral work, all of the things like downloading the text, checking it, checking whether it should be UK or US English, checking things 
online-they often take more time than the actual translation itself... and watching that video of myself I realize I actually translated the text quite quickly and it was everything else that took the time. (ProE4)

Something that was quite unexpected in the translators' comments about their workplace processes was how the same tools and translation aids were mentioned both positively and negatively. Even low-level decisions concerning punctuation have to be checked against what has been documented in style guides, parallel texts, concordances and, of course, translation memories. The translators' comments indicated that translation aids and tools have the potential to seriously constrain the translation process and thus limit translators' autonomy and creativity. Comments included: "none of the searches were helpful, so I can just translate it"; "I can decide myself"; "then I got the solution from my own brain". Nothing like this had emerged in the lab processes, yet it has important implications for how translation tools and aids might be changing the task of translation at the workplace. It is difficult for translators to come up with new, potentially very good solutions to translation problems if they are supposed to find and use existing solutions first (and their cognitive processing capacity is occupied with this). This suggests further directions for explorations at the workplace, some of which are outlined in section 3 .

\subsubsection{Eye tracking}

The use of eye tracking in the workplace remains a challenge for translation process research. In our project, the intention had been to investigate the amount of attention to the source and target text during various phases of the translation process as well as the number and direction of eye movements when translation problems were encountered. We carried out a feasibility analysis to determine whether our institute's eye-tracking monitor and software could be used at the LSP, but security regulations precluded it. Having a stand-alone eye tracker set up somewhere in the LSP offices would have been an option, but the ecological validity would have been little better than in a lab setting, since the translators would have to work at an unfamiliar workstation.

Trials were also carried out with eye-tracking glasses worn by four of the LSP translators for periods of one to two hours as they performed their normal work. Unfortunately, the quality of the eye-tracking recordings from the glasses was too poor to justify including this method of data collection in the study. However, they did provide some indications of issues associated with computer settings and workplace arrangements, which would be worth 
exploring further (see section 3). Newer models of eye trackers, such as those that can be installed under an existing monitor, may offer solutions that allow reliable eye-tracking data to be obtained under naturalistic workplace conditions.

\subsection{Completing the workplace study}

The data collection goals of the study had to be adapted as the on-site researchers coped with the realities of the workplace, and determining the completion date became a challenge. In the original design, all of the data collection methods were to be administered to all of the recruited translators. Due to attrition, this proved impossible (see table 2 for a summary of the data collected in the workplace study). Since security regulations at the LSP precluded the possibility of just turning on a screen recorder and letting it run every day for a certain length of time at each translator's workstation, non-confidential tasks had to be identified each day, processes recorded, and recordings edited to exclude anything unrelated to the translation task.

\begin{tabular}{|c|c|c|c|}
\hline Type of information & $\mathbf{n}$ & $\begin{array}{c}\text { Data collection } \\
\text { instrument }\end{array}$ & Form of data* \\
\hline $\begin{array}{c}\text { personal data, sociolinguistic } \\
\text { background, and education }\end{array}$ & 30 & questionnaire & transcript \\
\hline $\begin{array}{c}\text { self-report on typical translation } \\
\text { process }\end{array}$ & 30 & $\begin{array}{c}\text { semi-structured } \\
\text { interview }\end{array}$ & transcript \\
\hline $\begin{array}{c}\text { self-report about tool and resource } \\
\text { use }\end{array}$ & 29 & online questionnaire & $\begin{array}{c}\text { statistics, } \\
\text { comments }\end{array}$ \\
\hline $\begin{array}{c}\text { translation situation } \\
\text { selected translation process }\end{array}$ & 18 & $\begin{array}{c}\text { field notes } \\
\text { SCR }\end{array}$ & notes \\
\hline $\begin{array}{c}\text { specific aspects of translation } \\
\text { practice }\end{array}$ & 18 & $\begin{array}{c}\text { semi-structured } \\
\text { interview }\end{array}$ & $\begin{array}{c}\text { ST, TT, RVP, } \\
\text { tagged transcripts }\end{array}$ \\
\hline $\begin{array}{c}\text { translation processes } \\
\text { (about 20 hours/translator) }\end{array}$ & 225 & $\begin{array}{c}\text { various genres of STs } \\
\text { with SCR }\end{array}$ & $\begin{array}{c}\text { ST, TT, tagged } \\
\text { transcripts }\end{array}$ \\
\hline $\begin{array}{c}\text { quality assurance processes } \\
\text { (about 5.5 hours/translator) }\end{array}$ & 99 & $\begin{array}{c}\text { various genres of TTs } \\
\text { with SCR }\end{array}$ & $\begin{array}{c}\text { ST, TT, tagged } \\
\text { transcripts }\end{array}$ \\
\hline
\end{tabular}

* SCR=screen recording; ST=source text; TT=target text; RVP=retrospective verbal protocol

Table 2. Corpus of data from LSP staff translators collected during the CTP workplace study. 
The goals were redefined as 10 separate processes and at least 20 hours of processes per translator. Once all of the recordings were edited, the team realized that this goal had been reached for almost all of the translators ( $89 \%$ and $83 \%$, respectively). Since the lowest number of hours was just under 20 (namely, 19 hours and 21 minutes), the decision was made not to risk the ecological validity of the data collection by isolating specific translators and requesting more recordings. It was felt that this might put certain translators under pressure and was contrary to the procedure of letting the translators tell the on-site researchers when they had processes to be recorded.

The on-site researchers continued to work at the LSP workstation after the data collection phase had ended. For example, they edited recordings to delete sections unrelated to translation and to anonymize them. All of the processes were labeled with codes, and meta-information about the date, time, urgency, etc. was documented. By the time the data were released from the LSP to the project team, all of the data preparation had been completed and the analysis phase could begin.

One of the consequences of the lack of keylogging data was the necessity to develop a new way of coding and representing activities that a translator engages in during the translation process. The screen events were transcribed using XML-markup conventions based on the TEI (2008) guidelines, as suggested by Göpferich (2008: 72-81, 2010). The coding conventions had been developed and refined for the lab recordings (cf. Ehrensberger-Dow $\&$ Massey 2013), but it proved necessary to add several more codes to accommodate the activities recorded at the workplace (e.g., related to translation memory, interruptions in the process, comments for colleagues). However, the distribution of the core activities of writing, self-revision, consulting, and pausing did not seem to be very different between the lab and workplace in the processes examined thus far. About half of all the activities in the processes that the translators had commented on (one in the lab and one in the workplace) concerned self-revision, followed by writing, and roughly equal percentages of pausing and consulting activities (e.g., dictionaries, online searches). The results for the English-German and German-English translators are shown in figure 3, which includes the additional category of matches for the workplace processes, since translation memory was used there but not in the lab. 


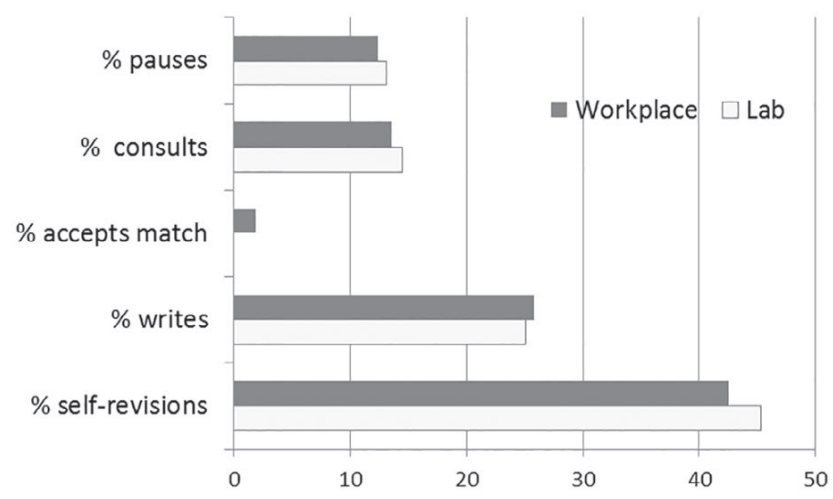

Figure 3. Percentages of activities during the translation processes in the lab and in the workplace $(n=14)$.

Activities in the translation process could also be charted over time, for example, to capture the iterative nature of the translation process that some of our translators commented on. The additional challenge that workplace processes present is how comparisons can be made when so many factors differ (e.g., translators, source texts, duration, use of translation memory). As more researchers become involved in workplace studies, solutions to this challenge are also likely to emerge.

\section{Further directions}

In summary, the choice of LSPs is crucial to the success of workplace research: they should be interested enough and large enough to handle the demands on staff resources that involvement in such a project inevitably entail. Before the project begins, researchers should spend time on the LSP premises in order to better anticipate and find solutions for possible problems and complications. If keylogging, screen recording, or eye tracking is planned, then sufficient lead time and the support of the LSP's IT services will probably be required. For ethical reasons, participation by individual translators should be voluntary, and their anonymity must be guaranteed by removing all identifying information from data for analyses. Any data or examples used for publication or educational purposes should be modified to ensure anonymity of the participating translators and to protect the LSPs from reputational risk. Confidentiality issues cannot be underestimated, and protocols should be worked out well before data collection begins. 
Despite or perhaps precisely because of these challenges, our experience suggests that doing translation process research in the workplace is well worth the effort. Long-term involvement with the realities of a translation workplace allow challenges to be dealt with and solutions to emerge that can lead to new research questions that might be just as relevant to practice and theory-building as the ones originally driving a research project, if not more so.

The motivation for the follow-up to the CTP project came directly from observations made in the workplace study. As discussed above (see 2.5.1), one of the sources of data was ethnographic observations, which revealed the constraints that the translators were working under. During the course of the study, some of those constraints changed for some of the translators, and it became increasingly clear that a closer examination of external influences would help us to understand their work demands and practices. We are convinced that good practices emerge when translators manage to break out of workplace constraints and free up their cognitive resources to allow for innovative solutions. Our new focus is on the cognitive and physical ergonomics of the translation workplace, which we are investigating in order to identify issues in human-computer interaction and physical conditions that might affect translation performance. If translators are unnecessarily constrained by the tools they are using and the system that they are working in, then it will be very difficult for them to demonstrate the adaptability and flexibility that is expected of them as professionals.

Workplace studies can be motivated by a pedagogical interest in knowing what professional translators do, in order to better prepare students for their future profession. They can also be motivated by economic concerns, such as ways of optimizing performance without detrimental effects on motivation and translator autonomy. Or they can be motivated by a desire to test theoretical models of extended cognition and situated activity. Understanding how translators cope with the demands on their cognitive resources while doing their job extends beyond the various agents in the situated activity of translation. It is also highly relevant for members of any professional group that operates at the human-computer interface.

\section{Acknowledgements}

The author would like to thank the research team, our industry partner, CLS Communication, and all of the participants for their valuable time and contributions to this project as well as to gratefully acknowledge the financial support of the Swiss National Science Foundation. Further information about 
CTP and its follow-up project can be found at <www.linguistik.zhaw.ch/iued/ capturing $>$ and <www.linguistik.zhaw.ch/ergotrans $>$.

\section{References}

AsAdi, Paula \& Candace Séguinot. (2005) "Shortcuts, strategies and general patterns in a process study of nine professionals." Meta 50:2, pp. 522-547. Electronic version available at: <http://www.erudit.org/revue/meta/2005/v50/ n2/010998ar.pdf>

AtKinson, Paul Anthony; Amanda Coffey; Sara Delamont; John Lofland \& Lyn Lofland (eds.) (2001) Handbook of Ethnography. London: Sage.

BRuneTTE, Louise; Chantal Gagnon \& Jonathan Hine. (2005) "The GREVIS project: Revise or court calamity." Across Languages and Cultures 6:1, pp. 29-45.

CAMPBELL, Stuart \& Berta Wakim. (2007) "Methodological questions about translation research.” Target 19:1, pp. 1-19.

CAO, Deborah \& Xingmin Zhao. (2008) "Translation at the United Nations as specialized translation." Journal of Specialised Translation 9, pp. 39-54. Electronic version available at: <http://www.jostrans.org/issue09/art_cao.pdf>

Christensen, Tina P. (2011) "Studies on the mental processes in translation memory-assisted translation - The state of the art." Trans-Kom 4:2, pp. 137-160. Electronic version available at: <http://www.trans-kom.eu/bd04nr02/transkom_04_02_02_Christensen_Translation_Memory.20111205.pdf>

Cravo Ana \& Josélia Neves. (2007) "Action research in translation studies." The Journal of Specialised Translation 7, pp. 92-107. Electronic version available at: <http://www.jostrans.org/issue07/art_cravo.pdf>

DÉSILETS, Alain; Christiane Melançon; Geneviève Patenaude \& Louise Brunette. (2009) "How translators use tools and resources to resolve translation problems: An ethnographic study." MT Summit XII - Workshop: Beyond Translation Memories: New Tools for Translators MT. Electronic version available at: <http://www.mt-archive.info/MTS-2009-Desilets-2.pdf>

EHRENSBERGER-DOW, Maureen \& Gary Massey. (2013) "Indicators of translation competence: Translators' self-concepts and the translation of titles." Journal of Writing Research 5:1, pp. 103-131. Electronic version available at: <http:// www.jowr.org/articles/vol5_1/JoWR_2013_vol5_nr1_Ehrensberger-Dow_ Massey.pdf>

Ehrensberger-Dow, Maureen \& Daniel Perrin. (2013) "Applying newswriting process research to translation.” Target 25:1, pp. 77-92.

ENGLUND Dimitrova, Birgitta. (2005) Expertise and Explicitation in the Translation Process. Amsterdam: John Benjamins.

GÖPFERICH, Susanne. (2008) Translationsprozessforschung. Tübingen: Narr. 
GÖPFERICH, Susanne. (2009) "Towards a model of translation competence and its acquisition: The longitudinal study TransComp." In: Göpferich, Susanne; Arnt L. Jakobsen \& Inger M. Mees (eds.) 2009. Behind the Mind. Methods, Models and Results in Translation Process Research. Copenhagen: Samfundslitteratur, pp. 17-43.

GOUADEC, Daniel. (2007) Translation as a Profession. Amsterdam: John Benjamins. HÉBERT-MALlOCH, Louise. (2004) "What do we know about a translator's day?" Meta 49:4, pp. 973-979. Electronic version available at: <http://www.erudit. org/revue/meta/2004/v49/n4/009805ar.pdf>

Holz-MÄntTÄrI, Justa. (1984) Translatorisches Handeln. Theorie und Methode. Helsinki: Suomalainen Tiedeakatemia.

KARAMANiS, Nikiforos; Saturnino Luz \& Gavin Doherty. (2011) "Translation practice at the workplace. Contextual analysis and implications for machine translation." Machine Translation 25:1, pp. 35-52.

KATAN, David. (2009) "Translation theory and professional practice: A global survey of the great divide." Hermes - Journal of Language and Communication Studies 42, pp. 111-153. Electronic version available at: <http://downloadl. hermes.asb.dk/archive/download/Hermes-42-7-katan_net.pdf>

Koskinen, Kaisa. (2008) Translating Institutions. An Ethnographic Study of EU Translation. Manchester: St. Jerome Publishing.

KuZNIK, Anne \& Joan M. Verd. (2010) "Investigating real work situations in translation agencies. Work content and its components." Hermes - Journal of Language and Communication Studies 44, pp. 25-43. Electronic version available at: <http://download2.hermes.asb.dk/archive/download/Hermes44-kuznik\%26verd.pdf>

LAFEBER, Anne. (2012) "Translation skills and knowledge - Preliminary findings of a survey of translators and revisers working at inter-governmental organizations." Meta 57:1, pp. 108-131.

LEBlAnC, Matthieu. (2013) "Translators on translation memory (TM). Results of an ethnographic study in three translation services and agencies." Translation $\mathcal{E}$ Interpretation 5:2, pp. 1-13. Electronic version available at: <http://www. trans-int.org/index.php/transint/article/view/228/134>

MARTIN, Tim. (2007) "Managing risks and resources: A down-to-earth view of revision." The Journal of Specialised Translation 8, pp. 57-63. Electronic version available at: <http://www.jostrans.org/issue08/art_martin.pdf>

MASSEY, Gary \& Maureen Ehrensberger-Dow. (2011a) "Investigating information literacy: A growing priority in translation studies." Across Languages and Cultures 12:2, pp. 193-211.

MASSEY, Gary \& Maureen Ehrensberger-Dow. (2011b) "Commenting on translation: Implications for translator training." Journal of Specialised Translation 
16, pp. 26-41. Electronic version available at: <http://www.jostrans.org/ issue16/art_massey_ehrensberger_dow.php>

Mossop, Brian. (2007) Revising and Editing for Translators. $2^{\text {nd }}$ Ed. Manchester: St. Jerome.

MuÑOz MARTín, Ricardo. (2010) "The way they were: Subject profiling in translation process research.” In: Mees, Inger M.; Fabio Alves \& Susanne Göpferich (eds.) 2010. Methodology, Technology and Innovation in Translation Process Research: A Tribute to Arnt Lykke Jakobsen. Frederiksberg: Samfundslitteratur, pp. 87-108.

Muñoz MARTín, Ricardo. (2012a) "Just a matter of scope. Mental load in translation process research.” Translation Spaces 1, pp. 169-188.

MuÑoz MARTín, Ricardo. (2012b) "Standardizing translation process research methods and reports." In: García Izquierdo, Isabel \& Esther Monzó Nebot (eds.) 2012. Iberian Studies on Translation and Interpreting. Bern: Peter Lang, pp. 11-22.

O'BRIEN, Sharon. (2012) "Translation as human-computer interaction." Translation Spaces 1, pp. 101-122.

PACTE. (2003) "Building a translation competence model." In: Alves, Fabio (ed.) 2003. Triangulating Translation. Perspectives in Process Oriented Research. Amsterdam: John Benjamins, pp. 43-66.

PACTE. (2011) "Results of the validation of the PACTE translation competence model. Translation Problems and translation competence." Alvstad, Cecilia; Adelina Hild \& Elisabet Tiselius (eds.) 2011. Methods and Strategies of Process Research. Amsterdam: John Benjamins, pp. 317-343.

RISKU, Hanna. (2002) "Situatedness in translation studies." Cognitive Systems Research 3, pp. 523-533.

RISKU, Hanna. (2009) Translationsmanagement. Interkulturelle Fachkommunikation im Informationszeitalter. $2^{\text {nd }}$ Ed. Tübingen: Narr.

RISKU, Hanna. (2010) "A cognitive scientific view on technical communication and translation. Do embodiment and situatedness really make a difference?" Target 22:1, pp. 94-111.

ROBERT, Isabelle S. (2008) "Translation revision procedures: An explorative study." In: Boulogne, Pieter (ed.) 2008. Translation and Its Others. Selected Papers of the CETRA Research Seminar in Translation Studies 2007. Electronic version available at: <http://www2.arts.kuleuven.be/info/bestanden-div/Robert.pdf>

TEI (2008) TEI P5: Guidelines for Electronic Text Encoding and Interchange. Electronic version available at: <http://www.tei-c.org/release/doc/tei-p5-doc/en/ $\mathrm{html} />$ 


\section{BIONOTE / KURZVITA}

Maureen Ehrensberger-Dow, PhD, is Professor of Translation Studies at the Institute of Translation and Interpreting, ZHAW Zurich University of Applied Sciences. Starting from a psycholinguistic interest in translation and multilingualism, her interdisciplinary research has recently focused more on language practitioners' strategies and expert knowledge. She is principal investigator of the federally-funded research project Capturing Translation Processes (CTP) and its follow-up project Cognitive and Physical Ergonomics of Translation (ErgoTrans). Her publications focus on the ergonomics of translation as well as on the development of translation expertise and its interaction with metalinguistic awareness, information literacy, and self-concept.

Maureen Ehrensberger-Dow, PhD, ist Professorin der Übersetzungswissenschaft am Institut für Übersetzen und Dolmetschen der Zürcher Hochschule für Angewandte Wissenschaften, ZHAW. Ausgehend von einem psycholinguistischen Interesse am Übersetzen und an der Mehrsprachigkeit legt sie in ihrer interdisziplinären Forschung den Fokus nun vermehrt auf die Strategien und das Expertenwissen von professionellen SprachmittlerInnen. Sie ist Projektleiterin des vom Schweizerischen Nationalfonds finanzierten Forschungsprojektes Capturing Translation Processes (CTP) und dessen Nachfolgeprojekt Cognitive and Physical Ergonomics of Translation (Ergonomie am Übersetzerarbeitsplatz, ErgoTrans). Der Schwerpunkt ihrer Publikationen liegt auf der Ergonomie des Übersetzens sowie auf der Entwicklung von Übersetzungsexpertise und deren Zusammenwirken mit metasprachlichem Bewusstsein, Informationskompetenz und dem übersetzerischen Selbstkonzept. 